\title{
APPLICABILITY OF GROUND PENETRATING RADAR ON DESERT ARCHAEOLOGICAL SITES: A CASE STUDY FROM THE SAQQARA NECROPOLIS IN EGYPT
}

\author{
Fabian Welc ${ }^{1}$, Radosław Mieszkowski ${ }^{2}$, Sebastian Kowalczyk ${ }^{2}$, Jerzy Trzciński ${ }^{2}$ \\ ${ }^{1}$ Institute of Archaeology, Cardinal Stefan Wyszyński University, ul. Wóycickiego 1/3, no. 23, \\ 01-938Warszawa,e-mail:f.welc@uksw.edu.pl \\ ${ }^{2}$ University of Warsaw, Faculty of Geology, Institute of Hydrogeology and Engineering Geology, \\ ul.Żwirki i Wigury93,02-089Warsaw,e-mails: r.mieszkowski@uw.edu.pl; jerzy.trzcinski@uw.edu.pl; \\ s.kowalczyk@uw.edu.pl
}

\begin{abstract}
This paper presents the preliminary results of ground penetrating radar sounding applied at the desert archaeological site in Saqqara (Egypt). The survey was carried out in 2012 within a project realized by Institute of Archaeology, Cardinal Stefan Wyszyński University in Warsaw and the Faculty of Geology, University of Warsaw. One of the key aims of the research was testing the application of ground penetrating radar to non-invasive surveys of desert archaeological sites. Radargrams obtained for area of so called the Dry Moat channel surrounding the Step Pyramid complex have shown the geological structure of its filling. It comprises among others debris-sand conglomerate of diluval origin characterized by a significant content of the clay fraction and clay minerals. Such lithological content strongly attenuate the propagation of EM waves, restricting the depth range of the GPR survey.

The conducted geophysical prospection west to the Step Pyramid in Saqqara has confirmed the high applicability of the GPR method in non-invasive studies of vast architectural structures, such as the monumental ditch surrounding the Step Pyramid known as the Dry Moat. It should summarised that high horizontal resolution obtained during GPR survey is a result of local geological structure of the searched area, i.e. strong lithological contrast of the sediments filling the Dry Moat, which, depending on their mineralogical composition.
\end{abstract}

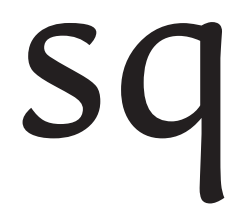

Key words: ground penetrating radar (GPR), archaeological site, Saqqara.

Manuscript received 7 June 2014, accepted 4 November 2014

\section{PRINCIPLES OF THE STUDY}

The application of ground penetrating radar (GPR) techniques in geological studies and non-invasive archaeological prospection is continuously growing since the 1980-ties (cf. Conyers, 2004). The method aids in locating underground funeral structures, graves (Doolittle \& Bellantoni, 2010; Schultz \& Martin, 2011), recognizing the course of moats and embankments or tracing the location of foundations and remains of older structures. The presently available GPR software allows for the visualization of processed measurement data both in 2D and 3D modes.

In general, the GPR method is based on emitting electromagnetic waves with frequencies in the range of high and ultra-high frequency radio waves (from $50 \mathrm{MHz}$ to $1.6 \mathrm{GHz}$ ) and registration of the impulses reflected from beds and lithological boundaries characterized by a specific permittivity (dielectric constant) and electrical resistivity. Despite the fact that the principle of the GPR method is relatively simple, the measurements and data processing may be rather complicated. This is caused by the complex nature of electromagnetic wave reflection, its interference (signal gain or loss), the very low level of the registered signal and a large number of disturbing factors (cf. Bristow \& Jol, 2003; Milson, 2003: 167-175; Karczewski, 2007).

At present, the most common form of GPR survey is reflection measurement used for the continuous record of geological structures, location of buried archaeological objects, elements of industrial installations and infrastructure. The prospection and its effectiveness depend on a number of factors, particularly:

- geological structure and thus the electrical parameters of the soil medium (electrical conductivity, attenuation factor, etc.). Soils having high conductivities rapidly dissipate the radar energy and restrict the investigation depths. The principal factors influencing the conductivity of soils are: porosity and degree of water saturation; amount and type of salts in solution; the amount and type of clay; and scattering (Doolittle \& Collins, 1995),

- water conditions, generally, soils have lower signal at- 


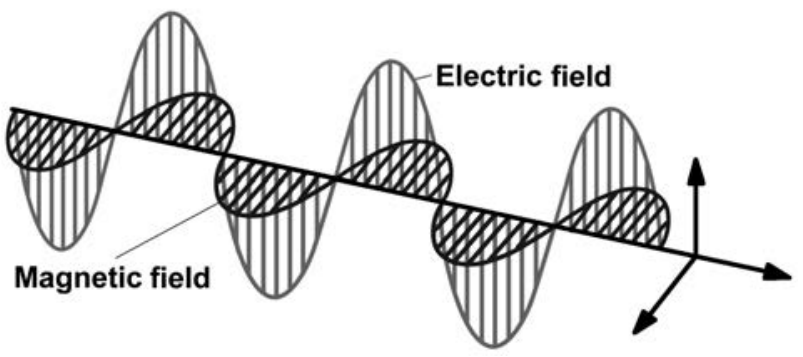

Fig. 1. Scheme of the electromagnetic wave propagation in a geological medium. Drown by F. Welc.

tenuation when dry than when wet (Doolittle \& Collins, 1995),

- frequency of the applied antenna.

Electromagnetic waves (EM) used in GPR method are transverse waves, i.e. in each point the vector of the electromagnetic field intensity ' $\mathrm{E}$ ' and the vector of magnetic induction ' $\mathrm{B}$ ' are perpendicular to one another and perpendicular to the direction of EM wave propagation in a medium (Karczewski, 2007) (Fig. 1).

The EM wave reacts to the changes of the dielectric constant of a medium $(\varepsilon)$, which calculated in relation to vacuum permittivity describes the electrical properties of the medium.

Waves are reflected, refracted and dispersed at the boundaries of media with a different dielectric constant, according to the laws of wave propagation. Waves reflected from the boundaries of media with a different dielectric constant and electrical resistivity corresponding to the lithological composition of the medium and the degree of its watering are used in GPR prospecting. In vacuum, EM waves propagate along straight lines with a velocity ' $c$ ' of about $3 \times 10^{8} \mathrm{~m} / \mathrm{s}$. In a medium filled with matter, the wave propagation velocity is lower and decreases with the increase of the dielectric constant.

The range of GPR prospecting depends thus on two main factors: frequency of the nominal transmitting antenna and electrical resistivity (soil electrical transmissivity) of the studied medium. The depth range increases with decrease of the antenna frequency. In turn, lower electrical resistivity results in a smaller depth prospection. In unfavourable cases of low-resistivity soils (thick beds of loams, clays and silts), attenuation of the EM waves may decrease the prospection range only to several meters, in some cases slightly over a dozen centimetres. Therefore, the contrast of dielectric properties of two geological media may influence the signal reflected from their boundary and in consequence the intensity of reflections registered by the radiogram.

The attenuation loss of the material is (David, 2004):

$$
L_{a}=8.686 \times 2 \times R \times 2 \pi_{f} \sqrt{\frac{\mu_{0} \mu_{r} \varepsilon_{0} \varepsilon_{r}}{2}\left(\sqrt{1+\tan ^{2} \delta}\right)-1}
$$

where:

$\mathrm{f}$ - frequency in $\mathrm{Hz}$,

$\tan \delta$ - loss tangent of material,

$\varepsilon_{r}$ - relative permittivity of material,

$\varepsilon_{0}-$ absolute permittivity of free space,

$\mu_{r}$ - relative magnetic susceptibility of material,

$\mu_{0}-$ absolute magnetic susceptibility of free space.
The radar system RAMAC GPR, produced by the Swedish company Mala Geoscience was used during the survey in Saqqara. The prospection was carried out with the application of screened transmitting antennas, monostatic with nominal frequency of the emitted EM wave of $100 \mathrm{MHz}$ and 250 $\mathrm{MHz}$, respectively. The device was equipped with a computer using Ramac Ground Vision software designed for the acquisition of measurement data directly in field. All obtained wavegrams were next processed in professional GPR software, Reflexw-Win of the German company Sendmeier Software. The particular profiles were shown on wavegrams. In each of them, the horizontal axis refers to real distances in meters, which correspond to the length of each profile. One side of the vertical axis shows the depth scale, whereas the second side displays the corresponding velocity of EM wave propagation in the studied medium $(\mathrm{ns} / \mathrm{m})$. The preliminary results of GPR survey in the Saqqara archaeological site have been already presented by Welc et al., (2013b).

During prospection, for comparison, the same registering parameters of the reflecting waves were used for the 250 $\mathrm{MHz}$ antenna, i.e. the step of inducing and registration of the emitted waves was $0.05 \mathrm{~m}$, at 8-ply signal stacking on the profile. This procedure is usually applied to achieve enhancement of low amplitudes of the usable reflections and restriction of the possibility of registry of accidental and lowamplitude noises.

Profiles registration was carried out in a wide time window range of $608 \mathrm{~ns}$. The time window was selected according to the following formula (Annan, 2001):

$$
T=1.3 \frac{2 \cdot h}{v}
$$

where:

$T$ - length of the expected time window,

$h$ - expected depth range,

$v$ - velocity of the EM wave in the medium.

Such range of the time window parameters were established based on data obtained by the Polish-Egyptian excavations conducted for many years in the area close to the geophysical survey. The team of Professor Karol Myśliwec has excavated a series of funerary structures dated to the Old Kingdom (c. 4200 B.P.). These are generally represented by tomb shafts cut in the rock with the depth from several to over a dozen meters, however not exceeding 20 m (cf. Kuraszkiewicz, 2013 for data on ancient Egyptian funerary architecture in West Saqqara).

The remaining parameters of the survey were as follows: - samples: 1766,

- frequency: 2903,

- frequency steps: 14 ,

- signal position: 380 ,

- raw signal position: 50093,

- distance flag (measured in fixed distance interval): 1 ,

- distance interval: $0.49 \mathrm{~m}$,

- antenna separation: $0.20 \mathrm{~m}$,

- stacks (number of compounds): 8 ,

- stop position (length of the profile): variable, from 100 to $200 \mathrm{~m}$.

A number of GPR processing procedures have been ap- 
plied; their main aim was the enhancement of the usable signal in relation to the background, i.e. noise. Crucial was also the improvement of correlation and continuity of the usable reflections, minimization of random noise and elimination of determined disruptions.

The applied so called $1 D$ filter procedures included:

- running average measurement,

- DC Shift,

- subtract-mean,

- gain and manual gain,

- move start time,

- bandpass frequency procedure.

The 2D filter procedures comprised:

- background removal,

- average xy filter,

- complex trace analysis. plied:

Among the advanced processing procedures were ap-

- deconvolution,

- F-k filtration,

- migration.

The last advanced processing procedure was compiling selected groups of echograms in a quasi-3D block-diagrams using 3D data interpretation mode in the Reflex View software. However, due to very small height differences in the measurement area, not exceeding $1 \mathrm{~m}$, topographic correction reflecting the actual terrain morphology was not applied.

\section{METHODS AND THE STUDY AREA}

The Saqqara necropolis is one of the most important Egyptian and world-class archaeological sites. The necropolis is located on the west bank of the River Nile, about $15 \mathrm{~km}$ to the south-west of the Cairo (Fig. 2). In geological terms, the area represents a limestone plateau reaching the height of 40 to $58 \mathrm{~m}$ above sea level, dipping at about $5-7^{\circ}$ to the west. Its eastern boundary is marked by a high cuesta separating the plateau from the floodplain of the River Nile (Fig. 3).

The top of Saqqara plateau is composed of Palaeogene carbonate rocks representing the Upper Eocene, which are unconformably covered by a thin layer of Quaternary deposits. The Upper Eocene series include hard and compact, light-creamy to brownish sandy-pelitic limestones interbedded with soft and poorly compact marly limestones; the complex represents the Upper Calcareous Beds of the Saqqara Member of the Maadi Formation. The series is about $22 \mathrm{~m}$

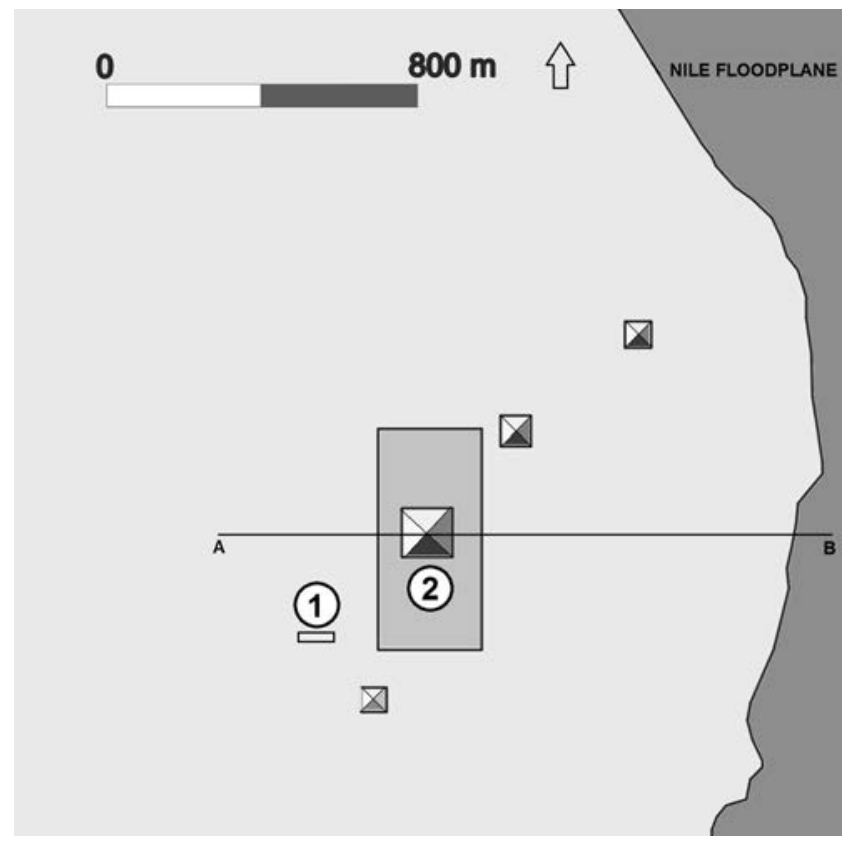

Fig. 2. General plan of Saqqara necropolis with marked cross section A - B (see below). 1 - area of the geophysical survey, 2 - Step Pyramid complex. Drawn by F. Welc.

thick and it is the main lithological component of the plateau (cf. Welc et al., 2013a).

Almost the entire area is covered by thick sequences of eolian sands, whose deposition began in the Saqqara area about 6000 years ago as a result of gradual retreat of the last Holocene pluvials, i.e. Nabta pluvial (Wendorf \& Schild, 1980; see also Schild, 2013). The youngest sediments in the study area comprises calcareous debris of anthropogenic origin that was accumulated since the early Old Kingdom times (c. 4600 B.P.) as a result of intense building works connected with the construction of kings' tomb complexes. The Holocene eolian cover has a variable thickness between 0.5 to $3 \mathrm{~m}$ (cf. Welc et al., 2013a).

Central Saqqara is overshadowed by the tomb complex of the $3^{\text {rd }}$ Dynasty Pharaoh Djoser - Netjerykhet (c. 4600 B.P.), whose main element is the 60-m high Step Pyramid representing the first Egyptian monumental structure entirely built of stone (Fig. 4). In the late 1970-ties, the Egyptian archaeologist Nabil Swelim spotted the outline of a wide moat surrounding the Step Pyramid complex from four sides

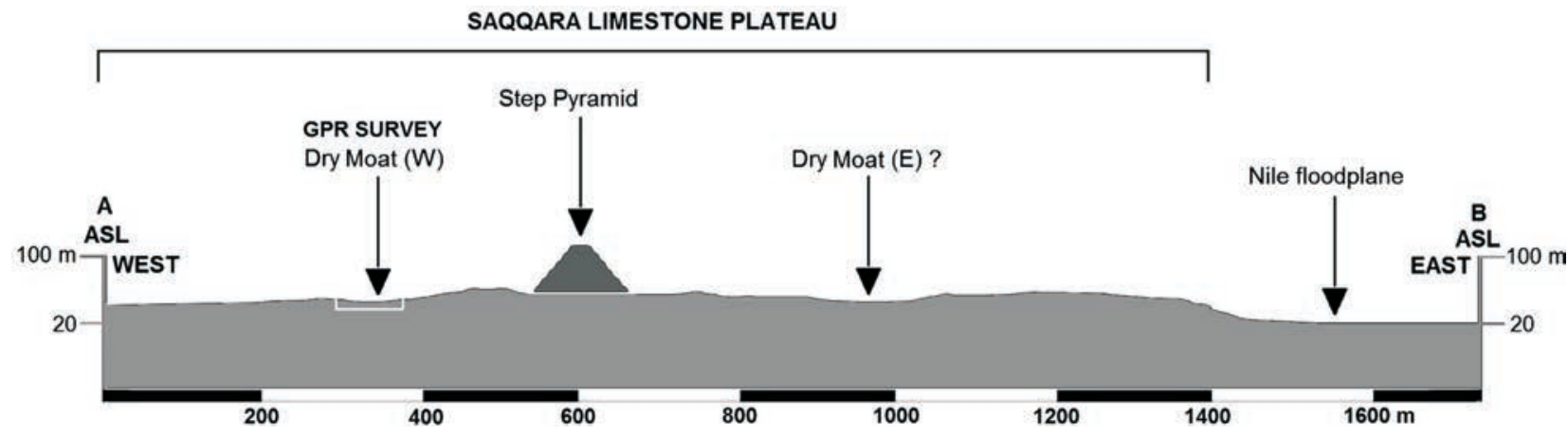

Fig. 3. Saqqara, section A - B, (see localisation above). Drawn by F. Welc. 


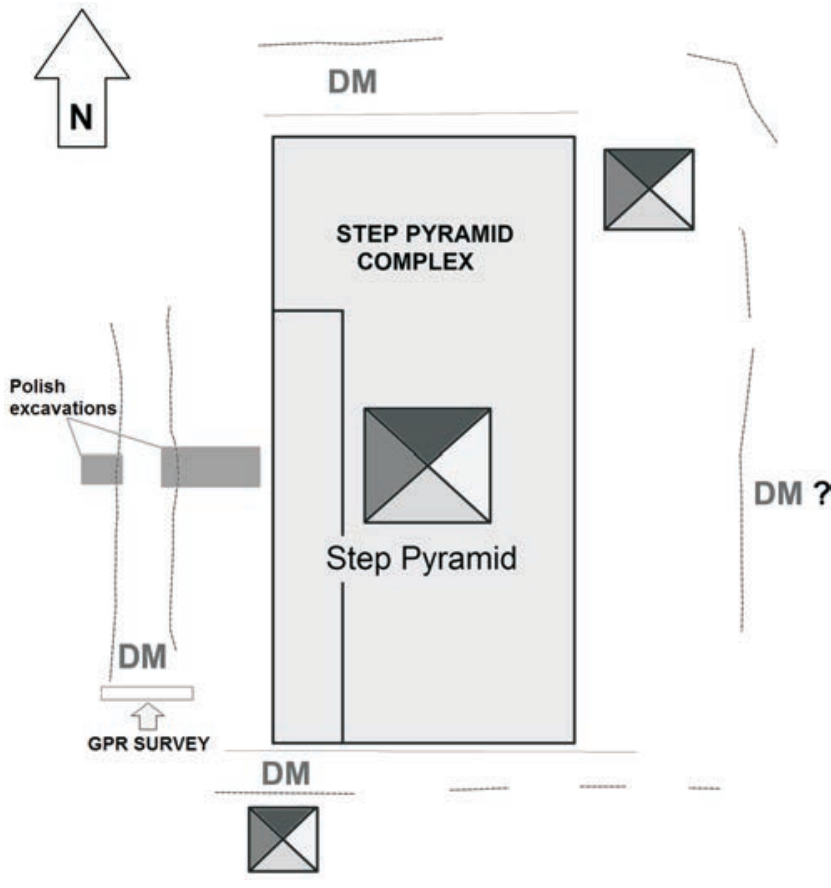

Fig. 4. Plan of the central Saqqara area with marked localisation of the geophysical survey and outline of the Dry Moat still visible on ground surface (DM). Drawn by F. Welc.

(Swelim, 1988, 1991). The structure was subsequently termed by him as the Dry Moat. According to Swelim (1988), the moat is a regular, c. $40 \mathrm{~m}$ wide, rock-cut ditch of variable depth, whose dimensions can be estimated on $750 \mathrm{~m}(\mathrm{~N}-\mathrm{S}) \times$ $600 \mathrm{~m}$ (E-W) (Fig. 4).
The most distinct part of the structure is the western section of the Dry Moat (Fig. 5: 1), which is located within the area of the Polish Archaeological Mission (Fig. 5: 3), supervised for many years by Professor Karol Myśliwiec from the Institute of Mediterranean and Oriental Cultures, Polish Academy of Sciences. During the 2012 campaign, a GPR was applied to determine the geometry of this enigmatic structure (cf. preliminary report, Welc et al., 2013b).

The GPR survey within the western section of the Dry Moat required the demarcation of several areas of variable length and width, of which the southernmost was marked as no. 7 (Fig. 5: 2). This is a 116-m long and 6-m wide, W-Eoriented strip (Fig. 6). A shielded, monostatic antenna with a frequency of $250 \mathrm{MHz}$ and an analogous antenna with a frequency of $100 \mathrm{MHz}$ were applied during the survey. The profiles were at a distance of $0.5 \mathrm{~m}$ from one another to allow the preparation of quasi-3D block-diagrams during further processing.

\section{DISCUSSION OF THE RESULTS OF GPR SOUNDING}

Based on the conducted measurements, the width of the Dry Moat in area no. 7 was estimated at about $60 \mathrm{~m}$. In all processed wavegrams the western margin of the ditch is visible at the 26 meter as a distinct, slightly oblique reflection surface, whereas its eastern margin can be recognized between the 85 and 87 meter (Figs. 7: A; 10:2;11). Both margins dip towards the centre of the depression at an angle of c. $65-70^{\circ}$. It should be noted that this is an apparent dip, resulting on the one hand from the surpassed depth scale in relation to the

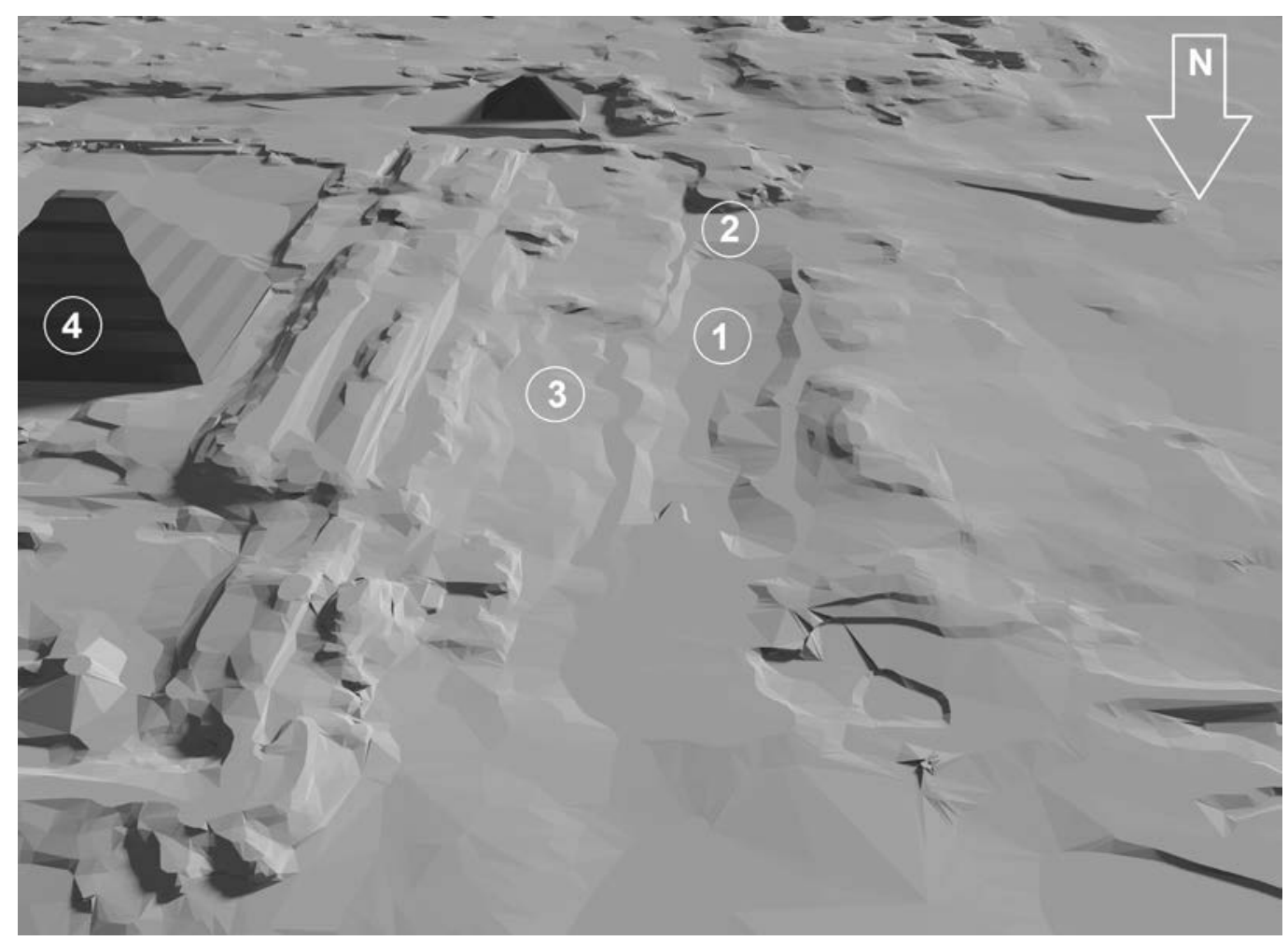

Fig. 5. Digital model of the area located to the west of the Step Pyramid Complex. 1 - western section of the Dry Moat, 2 -area searched by using georadar, - localisation of the Polish excavations, 4 - Step Pyramid. Made by K. Juszczyk and F. Welc. 


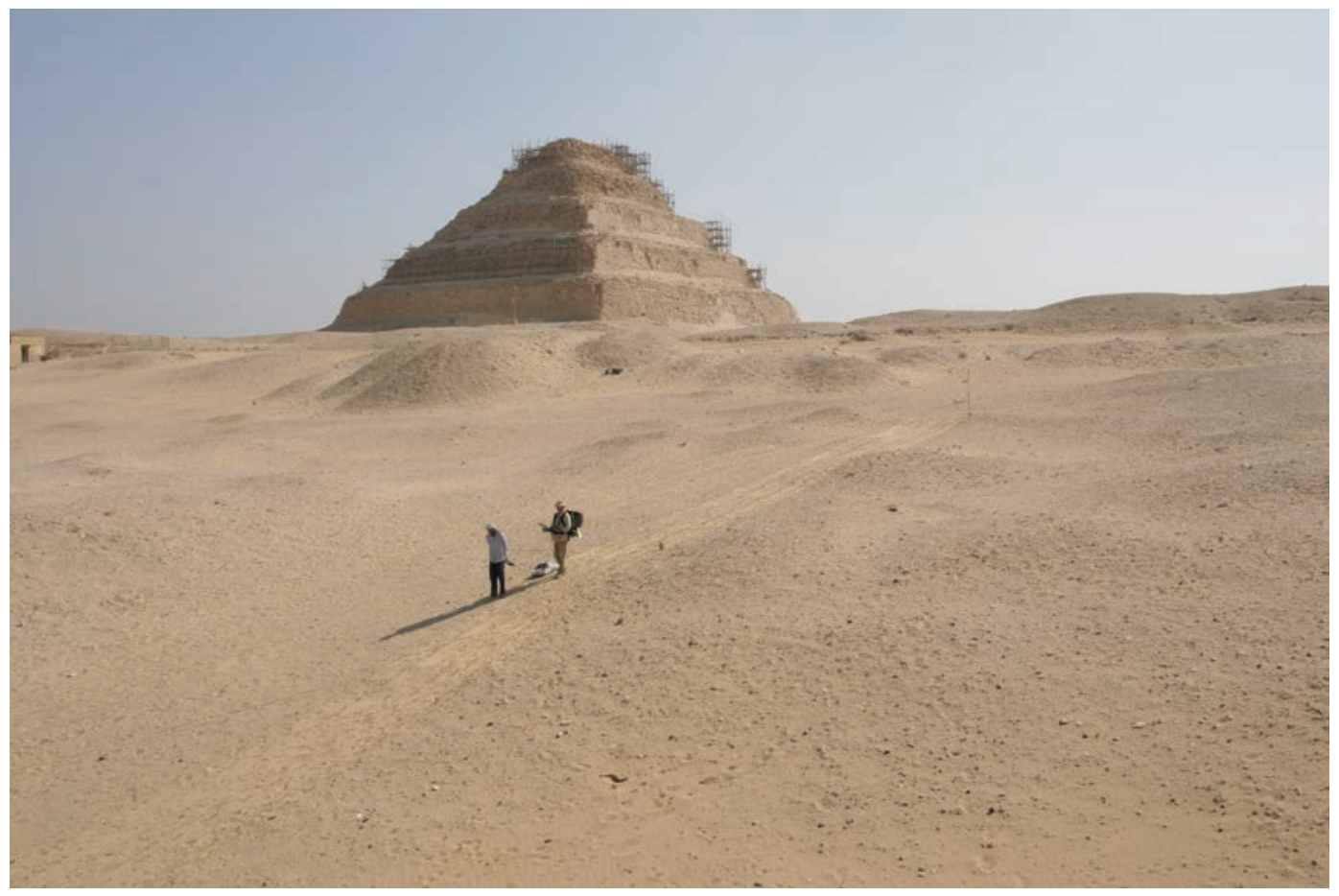

Fig. 6. Area no. 7 searched by using GPR. View from south - west. Photo F. Welc.
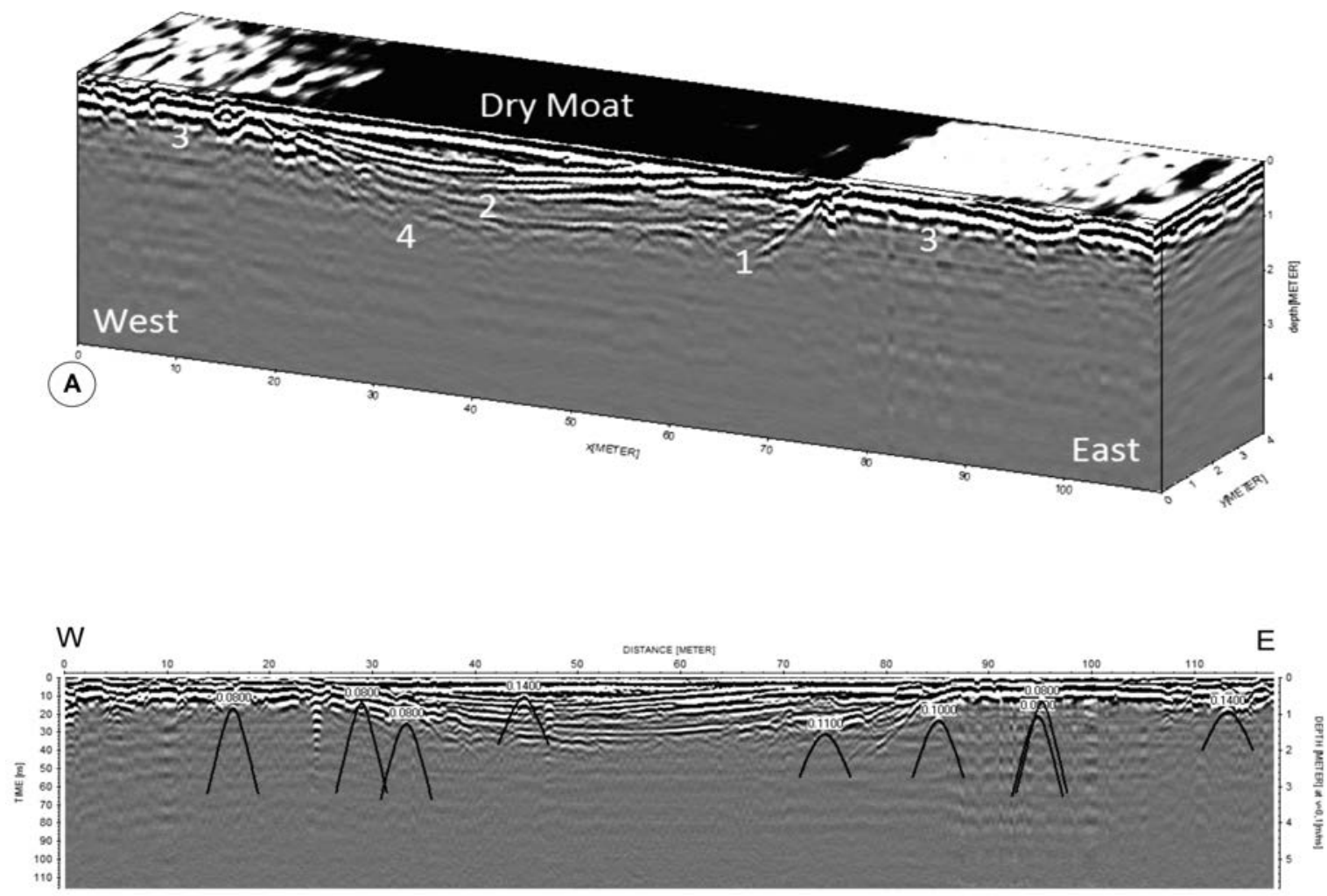

(B)

Fig. 7. A: GPR quasi-3D block-diagram of the western section of the Dry Moat. 1 - eastern edge of the DM, 2 - aeolian deposits filled upper part of Dry Moat, 3 - limestone rock massif, 4 - lower part of the Dry Moat filled by so called dakka. B: radargram with analysis of the shapes of diffraction hyperboles (see description in text). 


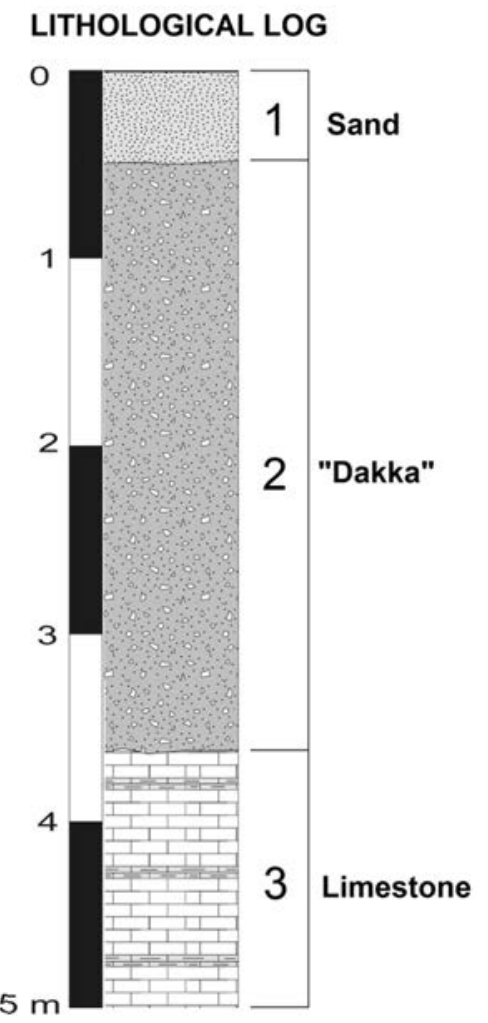

Fig. 8. Synthetic litological $\log$ for west Saqqara area. 1 wind-blown eolian sands, 2 - calcareous debris cemented with calcium carbonate with a sandy-clay-silty matrix, so-called dakka, 3 erosional top of Paleogene limestones. Drawn by F. Welc.

horizontal scale (distance), and on the other hand is the effect of horizontal translocation of the EM wave reflection point in relation to the receiving point. In effect, the record of the reflection point in the registered wave field takes place at a smaller depth than the actual depth. This causes that apparent dip decrease of the boundaries reflecting the EM waves can be observed in the registered wavegrams. In the studied case, it can be assumed that the actual dip of the Dry Moat edges exceeds c. $65^{\circ}$.

Characteristics of the deposits filling the studied fragment of the Dry Moat can be preliminarily determined by analysis of EM wave propagation velocity changes in the analysed geological medium and, more precisely, by the geometric analysis of the shapes of diffraction hyperboles (Fig. 7: B). In the upper (i.e. central) parts of the radargrams, i.e. to the depth of about 1.8-2 $\mathrm{m}$ are visible horizontal and oblique reflections corresponding most probably to the bedded sequences of eolian sands accumulated from the south (Figs. 7: A $-2 ; 10: 1 ; 11)$. This is confirmed by analysis of hyperbole shapes generated by shallow-lying objects (most probably mummies from the Ptolemaic and Roman period), which indicates wave velocities between 0.14 and $0.15 \mathrm{~m} / \mathrm{ns}$ that correspond to dry sands, characterized by the dielectric constant between 3 to 5 . The analysed radargrams record at least four generations of eolian deposits that can be correlated with the particular stages of ditch inundation or filling (Figs. 7: A -2, B; 9).

Below a distinct lithological boundary representing the base of the sand series, the electromagnetic impulses are strongly and rapidly attenuated by changes in the medium lithology, i.e. the Dry Moat filing (Figs. 9; 11). Results of previous studies of the Polish Archaeological Mission carried out on the western side of the Step Pyramid have allowed recognizing the stratigraphy in the study area in detail (Welc et al., 2013a). A synthetic lithological succession is as follows (Fig. 8):

- series 1: winnowed eolian sands, 0.5 to $1 \mathrm{~m}$ thick;

- series 2: calcareous debris cemented with calcium carbonate with a sandy-clay-silty matrix, known as the so-called dakka, 1 to $3 \mathrm{~m}$ thick;

- erosional top of Paleogene limestones unconformably co-

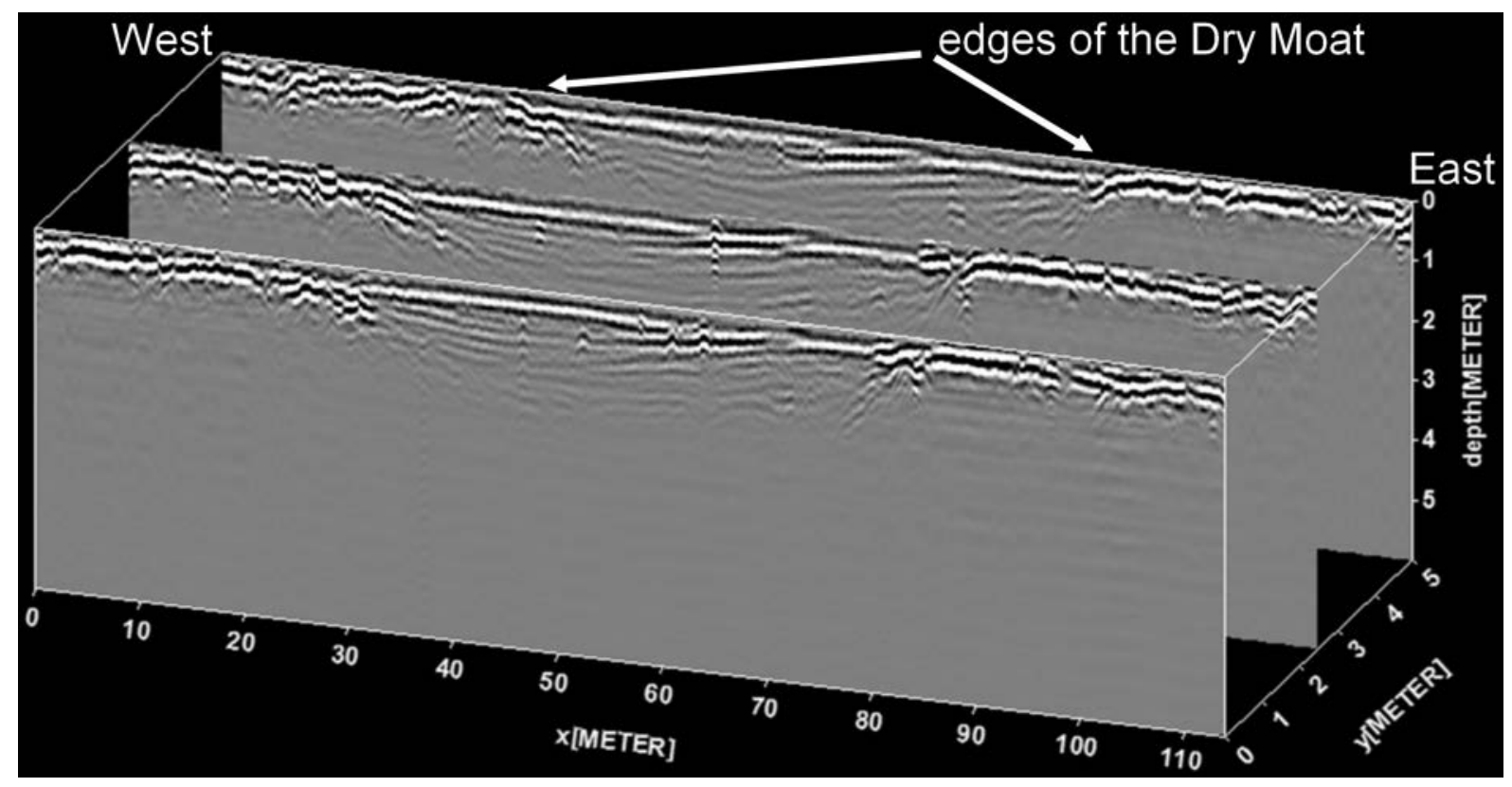

Fig. 9. GPR quasi-3D block-diagram of the western section of the Dry Moat with its edges marked by arrows. Processed by F. Welc. 

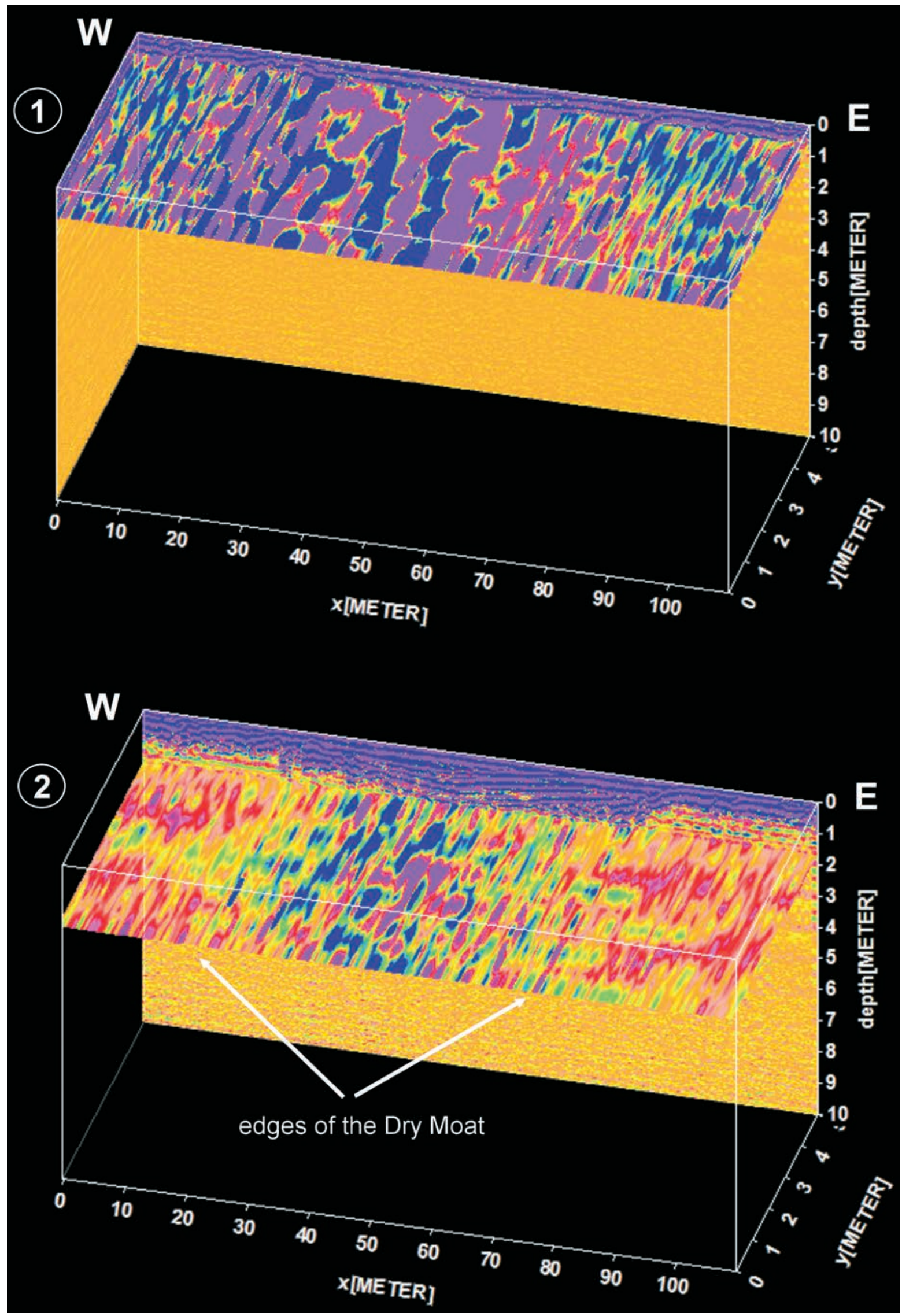

Fig. 10. GPR quasi-3D block-diagrams (slices) of the western section of the Dry Moat. 1: upper part of aeolian filling. 2: lower part of aeolian sediments with marked edges of DM. Processed by F. Welc. 


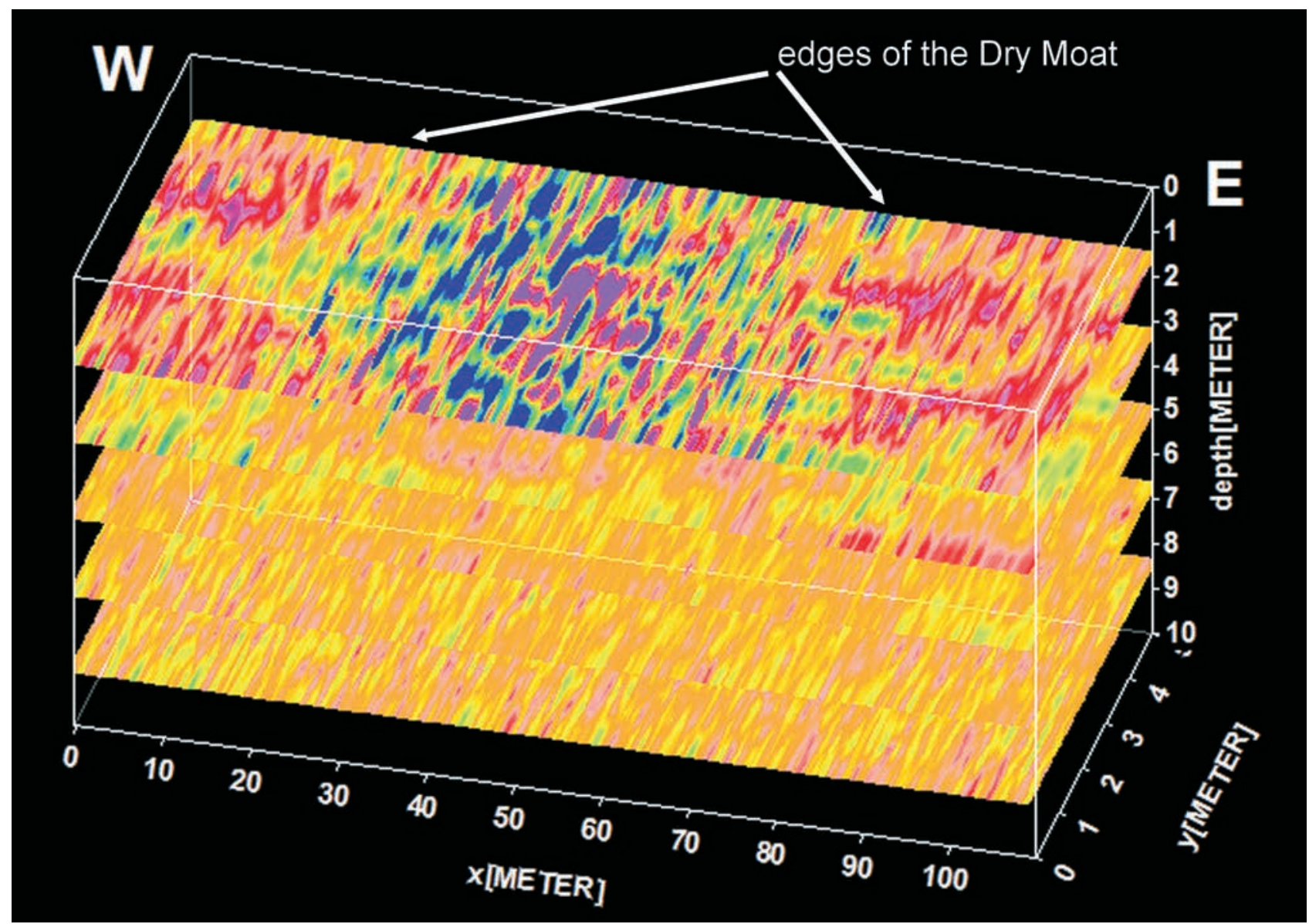

Fig. 11. GPR quasi-3D block-diagram (slices) of the western section of the Dry Moat. Processed by F. Welc.

vered by a thin bed of gravel and sand of the Pleistocene Edfu Formation (Welc et al., 2013a).

Thick deposits of second series underlying the eolian sands are generally of slope origin. They represent diluvia composed in the lower part of horizontally bedded silty sands and silty-clay sediments and in the upper part - of calcareous debris in various fractions (mostly fragments of local sandy and marly limestones), quartz pebbles, flints and numerous fragments of clay bricks, often eroded or almost completely disintegrated. These beds were deposited during the second part of the Old Kingdom (c. 4300-4200 B.P.) by periodic streams of rainwater generated in Western Saqqara (Welc \& Marks, 2013). At this time the area was systematically flooded by surface flows transporting debris and debris-mud material from the area lying above. In effect, the entire study area was periodically strongly watered. Lower and upper part of dakka still contain preserved small depressions filled with silty laminated sediments with a high organic content pointing to the presence of stagnating rainfall (Trzciński et al., 2010). Samples collected from the described diluvia have a similar lithology. They comprise fine and medium quartz grains and calcareous debris in a silty-clay fraction. Their characteristic feature is the relatively high content of plant remains (c. 5\%) and the presence of fragments of crushed or disintegrated clay bricks.

X-ray microanalysis (XRD) was applied to identify the clay minerals in described sediments. Basic automorphic minerals have been recognized in the samples such as albite, microcline, kaolinite and in small amounts also gypsum beside quartz and calcite (Welc \& Marks, 2013).

The presence of the clay fraction and clay minerals in sediments lying below the bedded sands filling the Dry Moat can be considered as the main cause of strong attenuation of the EM waves, which also has direct influence on reduction of the depth range of GPR prospection, because the attenuation coefficient in a geological medium is proportional to its conductivity, i.e. higher conductivity causes higher attenuation (cf. Benedetto \& Tosti, 2013; Tosti et al., 2013). If the attenuation coefficientis considered as $\mathrm{dB} / \mathrm{m}-\mathrm{a}$ logarithmic measure of the signal strength, the relationship may be presented as follows (Karczewski, 2007):

$$
\alpha=\frac{1.69 \cdot 10^{3} \cdot \sigma}{\sqrt{\varepsilon_{r}}}
$$

where:

$\alpha$ - the attenuation coefficient of the EM wave,

$\sigma$ - conductivity of the geological medium,

$\varepsilon_{\mathrm{r}}$-relative electrical permittivity of the geological medium.

In the studied case, the magnitude of EM wave attenuation is influenced by the geological composition of the diluvia (dakka) filling the lower part of the Dry Moat, including the particularly high content of clay minerals in the fine sand and silt fraction, which in places exceeds $40 \%$, as shown 
by the results of analysis of analogous deposits from the area of the Polish excavation in Saqqara (Welc \& Marks, 2013). Another important attenuation coefficient the waves is also the significantly higher porosity of the diluvia in relation to the covering eolianites. The frequency of the EM wave propagating in a non-uniform medium represented by debrissandy sediments is also a attenuation coefficient.

The relationship between wave frequency and attenuation is described as the Q or quality factor (Kjartansson, 1979). The relationship is given by:

$$
Q=\frac{\omega}{2 \cdot v \cdot \alpha}
$$

where:

$\alpha$ - the attenuation coefficient,

$v$ - the propagation velocity,

$\omega-$ the angular frequency.

In a real geological medium, the $\mathrm{Q}$ factor varies between 3 and 30 ; it is 14 to 30 for sand and only 10 for clay (Turner \& Siggins, 1994). In general, in geological media with the Q factor exceeding 5 there is a linear relationship between the EM wave attenuation coefficient and its frequency (Noon, 1996).

Numerous hyperboles of diffractional waves visible in all analysed wavegrams should be interpreted as probable reflections generated by the funeral structures (mummies) from the Ptolemaic-Roman period, of which over 600 have been documented in the area of the Polish- Egyptian excavation site located c. $180 \mathrm{~m}$ to the north (cf. Radomska et al., 2008).

\section{SUMMARY}

Radargrams and 3D compilations obtained for area no. 7 of the Dry Moat have shown the bimodal structure of its filling. It comprises c. 2-3 m of bedded sandy sediments underlain by a debris-sand conglomerate of diluval (flow) origin characterized by a significant content of the clay fraction and clay minerals. Such significant lithological contrast records the detailed structure of the upper sand beds and their lower boundary with the underlying diluvia, which due to a different mineral composition strongly attenuate the propagation of EM waves, restricting the depth range of the GPR survey.

Based on the obtained data it can be concluded that in the southern part of the Polish concession (area no. 7), the Dry Moat is a c. $60-\mathrm{m}$ wide ditch with a hardly determinable depth. The stratigraphy of the filling sediments indicates that the channel is deeper in the western part, however strong attenuation of EM waves does not allow even rough estimation of the depth differences.

The conducted geophysical prospection west to the Step Pyramid in Saqqara has confirmed the high applicability of the GPR method in non-invasive studies of vast architectural structures, such as the monumental ditch surrounding the Step Pyramid known as the Dry Moat. It should be stated that the high horizontal resolution obtained during the survey is a result of local geological conditions, i.e. strong lithological contrast of the sediments filling the Dry Moat, which, depending on their mineralogical composition, caused gain (eolian sands) or attenuation (dakka) of the EM waves.

\section{REFERENCES}

Annan, A. P. 2001. Ground-penetrating radar, Workshop Notes'. Sensors and Software Inc.

Benedetto, F., Tosti, F. 2013. GPR spectral analysis for clay content evaluation by the frequency shift method. Journal of Applied Geophysics 97: 89-96.

Bristow, C. S., Jol, H.M (eds.). 2003. Ground Penetrating Radar in Sediments. Geological Society Special Publications no. 211. London.

Conyers, L.B. 2004. Ground Penetrating Radar for Archaeology. Altamira Press, Walnut Creek, California.

David, J. D. 2004. Ground Penetrating Radar- $2^{\text {nd }}$ Edition. The Institution of Electrical Engineers. London.

Doolittle, J., A., Bellantoni, N., F. 2010. The search for graves with ground-penetrating radar in Connecticut. Journal of Archaeological Science 37: 941-949.

Doolittle, J., A., Collins, M., E. 1995. Use of soil information to determine application of ground penetrating radar. Journal of Applied Geophysics 33: 101-108.

Kjartansson, E. 1979. Constant Q-wave propagation and attenuation. Journal of Geophysical Research 84: 4737-4748.

Karczewski, J. 2007. Zarys metody georadarowej. Uczelniane Wydawnictwa Naukowo-Dydaktyczne AGH, Kraków.

Kuraszkiewicz, K. O. 2013. Architecture and Development of the Necropolis. Saqqara V, vol. 1. Neriton, Varsovie.

Milson, J. 2003. Field Geophysics. The Geological Field Guide Series. John Wiley and Sons, West Sussex.

Noon, D. 1996. Stepped-frequency radar design and signal processing enhances ground penetrating radar performance. Doctor dissertation, unpublished, Queensland.

Radomska, M., Kowalska, A., Kaczmarek, M., Rzeuska, T. I., Kopp, E., Kuraszkiewicz, K. O., Winnicki, J. K., Myśliwiec, K. (ed.). 2008. The Upper Necropolis. Saqqara III, vol. I. Warsaw, Neriton.

Schild, R. 2013. Early and Middle Holocene Paleoclimates in the South Western Desert of Egypt - The World Before Unification. Studia Quarternaria 30 (2): 125-133.

Schultz, J., J., Martin, M., M. 2011. Controlled GPR grave research: Comparison of reflection profiles between 500 and $250 \mathrm{MHz}$ antennae. Forensic Science International 209: 64-69.

Swelim, N. 1988. The Dry Moat of the Netjerykhet Complex. In: J. Baines, T. G. H, A. Leahy, A. F. Shore (eds.). Pyramid Studies and Other Essays Presented to I. E. S. Edwards. London: 32-41.

Swelim, N. 1991. Some remarks on the Great Rectangular Monuments of Middle Saqqara. MDAIK 47: 389 - 402.

Tosti, F., Patriarca, C., Slob, E., Benedetto, A., Lambot, S. 2013. Clay content evaluation in soils through GPR signal processing. Journal of Applied Geophysics 97, 69-80.

Trzciński, J., Kuraszkiewicz, K. O., Welc, F. 2010. Preliminary report on geoarchaeological research in West Saqqara. Polish Archaeology in the Mediterranean 19: Reports 2007: 194-208.

Turner, G., Siggins, A. F. 1994. Constant Q attenuation of subsurface radar. Geophysics $59: 1192-1200$.

Welc, F., Marks, L. 2013. Climate change at the end of the Old Kingdom in Egypt around 4200 BP: New geoarchaeological evidence. Quarternary International 324: 124-133.

Welc, F., Trzciński, J., Kaczmarek, M., Kozieradzka-Ogumnakin, I., Kowalska, A., Rzeuska, T.I., Godziejewski, Z., Weker, W., Myśliwiec, K. (ed.). 2013a. Geology, Anthropology, Finds, Conservation. Saqqara V, vol. 2. Neriton, Varsovie 2013: 323-343.

Welc, F., Trzciński, J., Kowalczyk, S., Mieszkowski. R. 2013b. Geophysical survey (GPR) in West Saqqara (Egypt): preliminary remarks. Studia Quarternaria 30 (2): 99-108.

Wendorf, F., Schild, R. 1980. Prehistory of the eastern Sahara. Academic Press, New York. 